\title{
11Driver's Attitude and its Influence on the Energy Waste of Electric Buses
}

Deborah Perrotta; José Luiz Macedo, Rosaldo J. F. Rossetti, Zafeiris Kokkinogenis; Laboratório de Inteligência Artificial e Ciência de Computadores Departamento de Engenharia Informática, Faculdade de Engenharia da Universidade do Porto, Portugal João Luiz Afonso and Deborah Perrotta; Centro Algoritmi, Universidade do Minho, Portugal Bernardo Ribeiro; CEllA - Centro para a Excelência e Inovação na Indústria Automóvel, Portugal

\subsection{Abstract}

The objective of this paper is to analyze the influence of different driver behaviors on the energy consumption of electric buses. It shows that risk-taking attitudes on traffic are not only dangerous to the driver, to the bus users and to the surroundings, but also promotes a poorer performance of the vehicle itself, increasing its energy consumption and reducing the amount of energy that can be recovered on regenerative braking.

Keywords: driver attitude; electric bus energy consumption; electric bus performance; risktaking behavior.

\subsection{Introduction}

Electric vehicles are seen as one of the key players to address the issue of global warming through its operation with zero tailpipe emissions and energy efficiency improvement. In the contemporary world, many countries are working on alternatives to replace internal combustion engine vehicles. For instance, in Europe, decision $N^{\circ} 406 / 2009 / E C$ of the European Parliament and of the Council of 23 April 2009 asks for the effort of the Member States on the reduction of greenhouse gases emissions by $20 \%$ until 2020 [1].

The 2007 Intergovernmental Panel on Climate Change report concluded that greenhouse gas emissions must be reduced by $50 \%$ to $85 \%$ by 2050 as an attempt to avoid many of the worst impacts of climate change. Reducing greenhouse gas emissions from transportation will likely require a broad range of strategies, such as increasing vehicle efficiency and reducing vehicle kilometers of travel. Public transportation can be one part of the solution [2], more specifically electric buses, which are quieter than regular buses, therefore promoting a better experience to public transport users, and also does not require much investment on infrastructure, as subways and trolleys for instance.

Nowadays, there are some electric buses in operation in some parts of the world and one of the main concerns is their high weight, which is mainly due to the amount of batteries they carry in order to have an adequate operation range. Nevertheless, it is crucial to investigate ways of optimizing an electric bus operation on the urban environment, promoting an efficient performance. This could lead in the future to a reduction of the bus weight, once it would require less energy to travel the same amount of kilometers, and thus less batteries. 
When talking about the operation efficiency of internal combustion vehicles, there is one factor that plays an important role on the fuel consumption: the driver's behavior. However, at this point it is relevant to define what characterizes an aggressive driving. It is known that there are three aspects of driving behavior that have been labeled as aggressive in the driving literature: (a) intentional acts of physical, verbal, or gestured aggression; (b) negative emotions (e.g. anger) while driving; and (c) risk taking [3]. For this paper, the focus will be on the third category, namely risk taking.

The risk-taking category includes behaviors such as speeding, running red lights, weaving through traffic, maneuvering without signaling, and frequent lane changing; it also comprises the dangers from lapses of attention while driving, typical for those who use the cell phone, eat, drink, smoke, or adjust a car stereo. Any of these behaviors may occur without the presence of negative emotion or intent to harm [4].

Generally, this type of behavior has implications on fuel consumption (for internal combustion vehicles) or energy consumption (for electric vehicles), once it is characterized for the opposite behavior of the so-called eco(logical)-driving. An ecological strategy is to anticipate what is happening ahead, and drive in such a way so as to minimize acceleration and braking, cruising at the optimal speed, and to maximize coasting time at stops [5]. In other words, it may be represented by a soft driving, especially restricting acceleration rates [6].

In this paper, it is intended to analyze the implications of risk taking attitudes of a driver towards the energy consumption of electric buses when compared to regular drivers. In order to do that, a mathematical model for an electric bus powertrain was developed and further implemented on the simulation program Simulink (a simulation package of the Matlab environment). This model was further integrated to the traffic simulator SUMO, allowing the bus simulated on Simulink to perform a route designed on SUMO that later gives feedback to Simulink in order to perform the calculations.

\subsection{Methodology}

An integrated simulation platform was developed in order to access the possible energy saving of a regular driver in comparison to a risk-taking one. This platform is characterized by the integration of two different simulators: a nanoscopic simulator represented by Simulink (Matlab environment), which accounts for the representation of the powertrain behavior, and a microscopic simulator represented by SUMO, which accounts for the routes that the bus is supposed to perform, the interactions of this bus with other vehicles, and the stops at bus stops and traffic lights.

The Simulink model calculates the torque needed to operate the vehicle at each moment, considering aerodynamic drag, tire rolling resistance, climbing grade and vehicle inertia effects [7]. The required total torque needed to drive the wheels at each moment at a given speed is converted to power, and further converted to energy, which is the energy required to perform the route designed at SUMO [8], [9]. This model also calculates the amount of energy that is wasted when the vehicle brakes and that could be further recovered through regenerative braking [10], as long as the analyzed electric bus powertrain has this ability.

As mentioned before, SUMO plays an important and central role on the calculations performed by Simulink. It allows the microscopic interactions between the bus and the other cars, making it possible to represent the dynamic behavior of the driver regarding acceleration and braking. Furthermore, it also allows the modeling of any desired route, including bus stops, which are crucial for the calculations. 
A more simple approach was handled in order to facilitate the results analysis. Basically, the parameter used to differentiate the risk taking driver from the regular one is the acceleration rate, either on acceleration episodes or negative braking, behaviors that do not characterize a smooth drive [6]. Risk-taking drivers have a higher acceleration rate in both cases, and this parameter is crucial for the calculations performed on Simulink [7]. The route takes into consideration the traffic lights, the bus stops and the interaction with other vehicles, in order to have more realistic results.

\subsection{Simulation Test-Bed}

A random route was taken and modeled, considering as base reference the region of Aliados, in the city of Oporto, Portugal. On this route, some bus stops were defined and it was assumed that the bus would stop 20 seconds at each one of them. Stops at red traffic lights were also considered. In Figure 11-1 it can be observed that region of Aliados and a zoom-in on a certain area, where the large green rectangles are bus stops and the smaller yellow one is the bus, stopped in front of the bus stop (more specifically on the left avenue).

For calculation purposes, it was assumed that the absolute acceleration rates for the risktaking driver are twice as the ones from regular drivers and that the deceleration rate is nearly $50 \%$ higher (Table 11-1). It is relevant to point out that none of these values surpass the technical restrictions of the electric bus.

Table 11-1: Acceleration/ Deceleration rates for simulation.

\begin{tabular}{lcc}
\hline Driver's profile & Acceleration $\left(\mathrm{m} / \mathrm{s}^{2}\right)$ & Deceleration $\left(\mathrm{m} / \mathrm{s}^{2}\right)$ \\
\hline Regular & 2.6 & 4.5 \\
Risk taking & 5.2 & 6.5 \\
\hline
\end{tabular}

The simulation was then performed twice for exactly same route: one using regular acceleration rates, based on the normal operation of the bus, and another for the "aggressive" behavior, which for this paper is characterized by higher values of acceleration rates and faster braking.

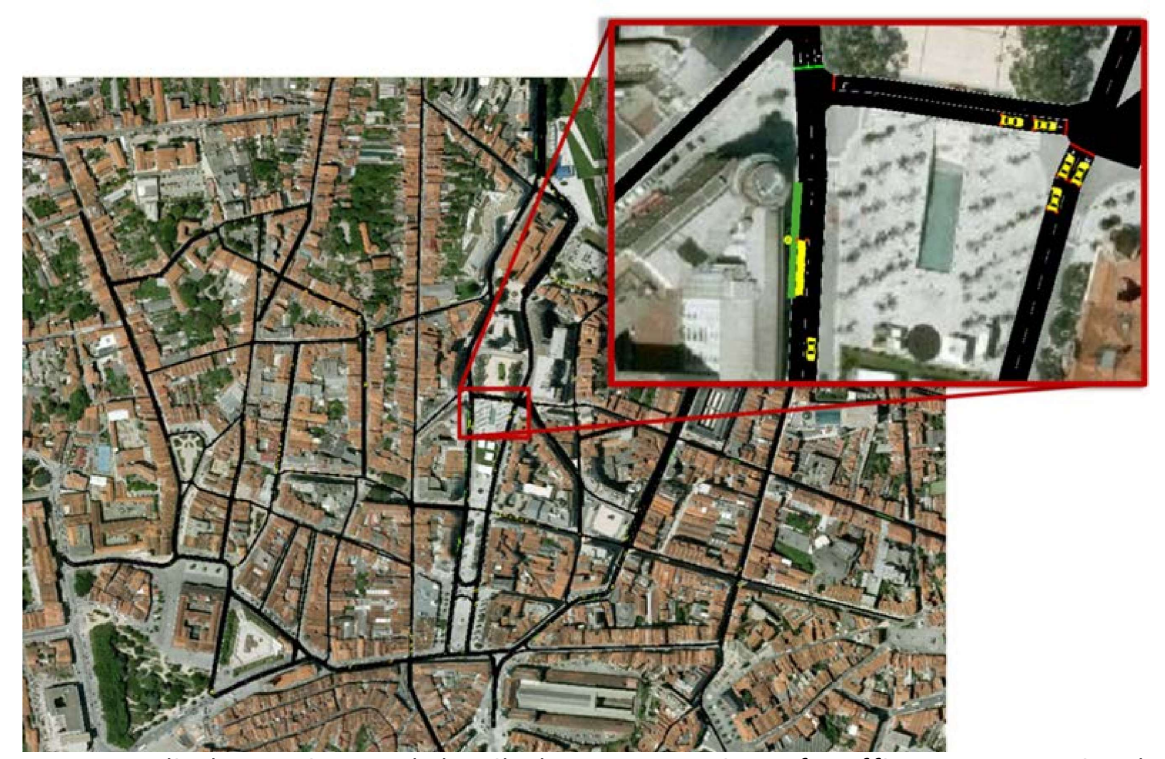

Figure 11-1: Aliados region and detailed representation of traffic on SUMO simulator. 


\subsection{Results}

The first analyzed parameter was the amount of energy spent to perform the route. In Figure $11-2$ it can be seen that the aggressive driver spent $17 \%$ more energy $(0.100 \mathrm{kWh})$ than the regular driver $(0.087 \mathrm{kWh})$ to complete exactly same route.

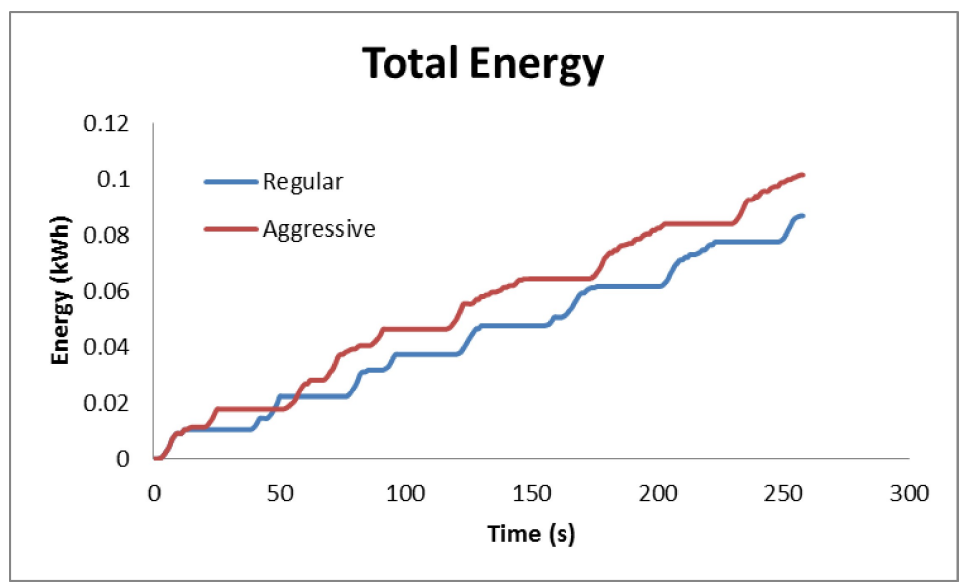

Figure 11-2: Comparative plot of the amount of energy spent by each electric bus driver.

The second analyzed parameter was the amount of energy that is wasted during the braking episodes on the resistance forces to the movement, namely resistance to the air, resistance to the ground and inertia. All these forces depend significantly on the acceleration rate, thus it is expected some discrepancy between the outcomes from both drivers.

In Figure 11-3, it can be observed that the aggressive driver wastes $0.014 \mathrm{kWh}$ in all braking episodes of this route, while the regular driver spends half of this amount: $0.007 \mathrm{kWh}$. This parameter is extremely important to calculate the potential to recover energy on braking episodes. Having a risk taking attitude contributes negatively to this recovery, once this generates a higher boost of energy in such a small period of time (i.e., a braking episode), that batteries would struggle to absorb, due to their low power density [11].

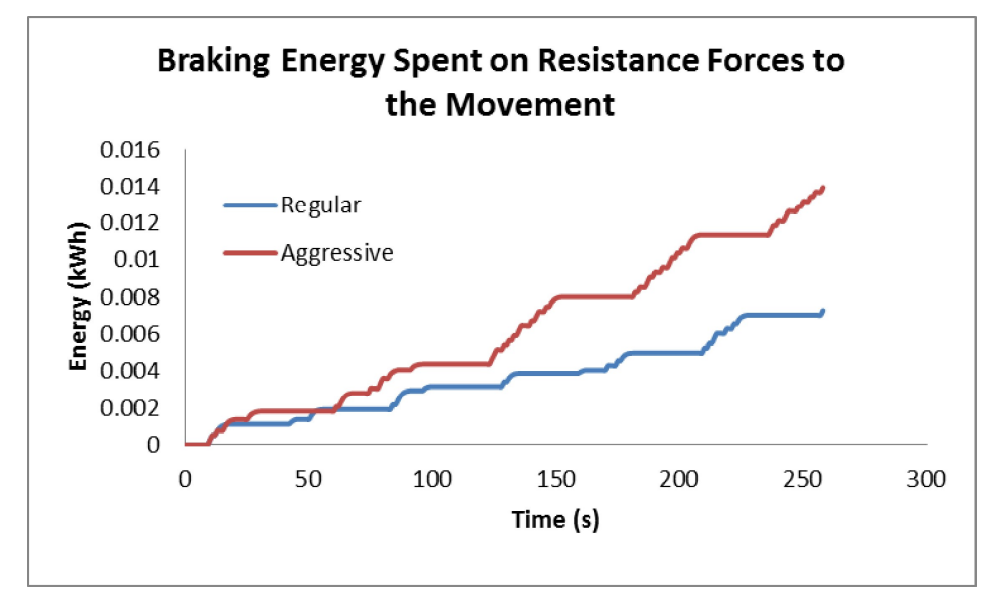

Figure 11-3: Comparative graph of the amount of energy wasted on braking episodes.

\subsection{Conclusions and Future Work}

In conclusion, with this work it became clear how badly can driver's attitude affect the energy consumption of an electric bus. Not only is risk-taking behavior dangerous for the driver and the others but it also contributes negatively to an efficient driving performance. In this paper, the case of an electric bus was analyzed and it could be observed that a simple risk-taking attitude, such as accelerating or braking more intensely, has a huge influence on the bus 
performance, either regarding the amount of energy spent to complete a certain cycle, or regarding the potential of energy recovery from the regenerative braking episodes.

Future work intends to investigate deeper into this matter by the creation of simulation agents, which will mimic the human reaction to adverse traffic conditions, thus allowing a more detailed analysis.

\subsection{Acknowledgment}

This work is financed by FEDER Funds, through the Operational Programme for Competitiveness Factors - COMPETE under the project 13844. Deborah Perrotta thanks FCT (Fundação para a Ciência e Tecnologia) for PhD scholarship (SFRH/BD/51256/2010) under the scope of the MIT Portugal Program in Engineering Design and Advanced Manufacturing Leaders for Technical Industries focus area.

\subsection{References}

[1] "Summaries for EU Lesgislation." [Online]. Available: http://europa.eu/legislation_summaries/energy/european_energy_policy/en0008_en.ht $\mathrm{m}$.

[2] Federal Transit Administration (FTA), "Public Transportation ' s Role in Responding to Climate Change," 2010.

[3] C. S. Dula and M. E. Ballard, "Development and Evaluation of a Measure of Dangerous, Aggressive, Negative Emotional, and Risky Driving1," Journal of Applied Social Psychology, vol. 33, no. 2, pp. 263-282, Feb. 2003.

[4] C. S. Dula and E. S. Geller, "Risky, aggressive, or emotional driving: Addressing the need for consistent communication in research," Journal of Safety Research, vol. 34, no. 5, pp. 559-566, Jan. 2003.

[5] M. Kamal, M. Mukai, J. Murata, and T. Kawabe, "Development of Ecological Driving Assist System Model Predictive Approach in Vehicle Control," in 16th ITS World Congress and Exhibition on Intelligent Transport Systems and Services, 2009, pp. 1-11.

[6] M. Miyatake, "Theoretical Study on Eco-Driving Technique for an Electric Vehicle Considering Traffic Signals," in Power Electronics and Drive 2011 IEEE Ninth International Conference on Systems (PEDS), 2011, no. December, pp. 5-8.

[7] D. Perrotta, A. Teixeira, H. Silva, and B. Ribeiro, "Electrical Bus Performance Modeling for Urban Environments," in SAE 2012 World Congress, 2012.

[8] J. Larminie and J. Lowry, Electric Vehicle Technology Explained. John Wiley \& Sons Ltd, 2003, p. 62; 183-186.

[9] M. Ehsani, K. M. Rahman, and H. a. Toliyat, "Propulsion system design of electric and hybrid vehicles," IEEE Transactions on Industrial Electronics, vol. 44, no. 1, pp. 19-27, 1997.

[10] S. R. Cikanek and K. E. Bailey, "Regenerative braking system for a hybrid electric vehicle," in Proceedings of the 2002 American Control Conference (IEEE Cat. No.CH37301), 2002, pp. 3129-3134.

[11] A. Chu and P. Braatz, "Comparison of commercial supercapacitors and high-power lithium-ion batteries for power-assist applications in hybrid electric vehicles I. Initial characterization," Journal of Power Sources, vol. 112, no. 1, pp. 236-246, Oct. 2002. 